ESJ Social Sciences

\title{
Culture et Modèle de l'acteur Socio-économique : Cas du Congo
}

\author{
Hilarion Josaphat Mfouka
}

Enseignant chercheur, Université Marien Ngouabi de Brazzaville, Congo

Doi:10.19044/esj.2021.v17n32p192

Submitted: 05 December 2020

Accepted: 11 May 2021

Published: 30 September 2021
Copyright 2021 Author(s)

Under Creative Commons BY-NC-ND

4.0 OPEN ACCESS

Cite As:

Mfouka H.J. (2021). Culture et Modèle de l'acteur Socio-économique : Cas du Congo. European Scientific Journal, ESJ, 17 (32), 192.

https://doi.org/10.19044/esj.2021.v17n32p192

\section{Résumé}

Cet article montre que la situation d'existence d'un acteur détermine l'interaction. Pour le démontrer, on caractérise cette situation par une culture qui impacte l'acteur socio-économique à travers la personnalité de base ou l'organisation de l'interaction. La personnalité de base ou l'organisation incarne les attitudes et comportements communément reconnus ou partagés. La culture et la personnalité de base sont des dispositions régulières du capital humain mobilisées dans la décision et l'action à travers une organisation. Dans le cas du Congo, la culture est appréhendée à travers des hypothèses résultant d'un constat, d'un vécu ou d'une perception régulière des congolais ou de l'environnement social du Congo. De ces hypothèses, on anticipe les attitudes et comportements attendus des acteurs à partir de la norme sociale. Les hypothèses ont été testées et confirmées dans une enquête. Elles sont aussi confirmées par d'autres analyses et données sur le Congo. Les résultats montrent que la culture mise en évidence est irrationnelle -au sens de l'économie ou de la gestion- et favorable au sous-développement. L'irrationalité se traduit surtout par la déviance, l'opacité, l'absence de liberté ou d'État de droit, le mysticisme et les traditions. Cette irrationalité s'accompagne d'une culture du sous-développement caractérisée par la pauvreté, la dépendance à l'étranger et la prépondérance des activités informelles. Il en découle une personnalité sociale inadaptée face aux défis du développement et de l'intégration dans l'économie mondiale. 
Mots-clés: Interaction, culture, personnalité de base, organisation, acteur ou agent socio-économique, développement

\title{
Culture and Model of the Socio-economic Actor: Case of Congo
}

\author{
Hilarion Josaphat Mfouka \\ Lecturer and Researcher, Marien Ngouabi University of Brazzaville, Congo
}

\begin{abstract}
This article shows that the existence situation of an actor determines the interaction. To demonstrate this, we characterize this situation by a culture that impacts the socio-economic actor through the basic personality or the organization of the interaction. The basic personality or organization embodies commonly recognized or shared attitudes and behaviors. Basic culture and personality are regular dispositions of human capital mobilized in decision and action through an organization. In the case of Congo, culture is understood through hypotheses resulting from an observation, experience, or regular perception of the Congolese or of the social environment of the Congo. From these assumptions, the expected attitudes and behaviors of the actors based on the social norm was anticipated. The hypotheses were tested and confirmed in a survey. They are also confirmed by other data analysis on Congo. The results show that the highlighted culture is irrational - in the sense of economics or management - and favorable to underdevelopment. Irrationality manifests itself above all in deviance, opacity, lack of freedom or the rule of law, mysticism, and traditions. This irrationality is accompanied by a culture of underdevelopment characterized by poverty, dependence on foreign countries, and the preponderance of informal activities. The result also shows a social personality unsuited to the challenges of development and integration into the world economy.
\end{abstract}

Keywords: Interaction, culture, basic personality, organization, socioeconomic actor or agent, development

\section{Introduction}

L'interaction n'est pas un processus neutre. Elle est stimulée dans un environnement aux contextes variables. Cet environnement est une situation d'existence qui motive l'implication ou l'engagement des acteurs socioéconomiques. L'acteur est un individu, un groupe ou une organisation. La situation d'existence est un cadre social et économique caractérisé par une culture. Les acteurs y rencontrent ou y conçoivent des problèmes qu'ils 
essaient d'apprécier et de résoudre de manière stable dans une culture. La culture forge et impacte la perception des acteurs, leurs décisions et leurs actions. L'acteur n'est plus quelconque. Il n'est plus cet homo œconomicus universel. Il devient spécifique et situé dans une culture à partir de laquelle il s'est adapté à sa situation d'existence. La culture est un sujet transversal des sciences sociales (ADEME, 2016 ; Cuche, 2016) et un fondement de la théorie du capital humain (Becker, 1993), de l'économie comportementale (Kahneman et al., 1982 ; Kahneman \& Tversky, 2000 ; Thaler, 2018 ; Becker, 1993 ; Sen, 1985, 1993, 1999) et du développement (UNRISD, 2014).

Le capital humain est un potentiel fondamental d'interaction correspondant aux capacités productives d'un acteur. Résultant de la socialisation et de l'intégration sociale, il dépend de la santé mais aussi de l'éducation, des droits et libertés accordés aux individus. Le capital humain est donc culturel. Il peut être décrit par un ensemble d'attitudes et de comportements d'adaptation dans la situation d'existence. Il est un déterminant du développement : la croissance et l'amélioration continues des structures institutionnelles, sociales, économiques et culturelles (Boudon et $a l ., 2012)$ reposent d'abord sur le capital humain. La croissance a des déterminants politiques et sociaux (Facchini, 2008). Ces déterminants sont liés à la culture et à l'organisation qui, à leur tour, influencent les attitudes et comportements des individus, impactent les paramètres socio-économiques tels que la natalité, le temps de travail, l'épargne, l'éducation, les coûts de transaction, les choix individuels...- en fonction de la confiance et des valeurs. La confiance est favorable à la croissance (Laporta et al., 1999). Les valeurs sont plus ou moins favorables au développement. Si l'homogénéité culturelle favorise les échanges et réduit le coût des contrats, la diversité culturelle (comme les ethnies, religions et langues) peut inspirer la méfiance ou être propice aux échanges et à l'opportunité économique comme dans le cas des avantages comparatifs ou de la différence de dotation en facteurs (Facchini, 2008).

D'après les Nations-Unies (UNRISD, 2014), le développement repose sur les structures sociales, les institutions et l'agence (capacité de choix ou d'influence sur la décision). Les structures sociales sont des modes de stratification et de différenciation. Elles posent la question des statuts, des inégalités et des discriminations. Il faut noter que «moins d'inégalités favorise la croissance économique » (Barou et al., 2016, p.254, 1.11-12). Les institutions sont des règles de comportement. L'activité économique en dépend (Baumol, 1990). La non-conformité aux institutions pose des problèmes de déviance. Dans un rapport sur la corruption au Congo (République du Congo, 2018), le FMI reconnaît l'impact des institutions, de la bonne gouvernance et de la corruption sur la croissance, la réduction des inégalités et la confiance des citoyens. La question de l'agence sociale est liée 
à la capacité de choix, à la liberté d'expression et aux processus décisionnels. Dans son analyse du développement, Sen (1999) insiste sur le lien entre la pauvreté, les capacités ou capabilités et les droits. Les capabilités, potentiel que procure un bien ou un service, résultent des dotations en capital humain et en droits. La richesse ou le revenu ne suffit pas pour apprécier le développement. L'indice du développement humain ne repose pas que sur le revenu mais aussi sur l'éducation et la santé (Raffinot, 2015). D'autres indices comme l'indicateur de pauvreté humaine (IPH) tiennent compte de la longévité, l'instruction et les conditions de vie (Ibid. ). Les questions d'attitudes et de comportements, du capital humain, de décision et de développement sont liées à la culture et à la personnalité des acteurs socioéconomiques qui sont des individus et des organisations. L'interaction étant cependant un processus affecté par une certaine contingence, du fait de l'interdépendance et de la réciprocité des acteurs, elle génère une relative imprévisibilité (Durand et Weil, 2006). Le capital humain -déjà soumis au principe de rationalité limitée (Simon, 1983) et du pouvoir discriminant imparfait des acteurs (Roy, 1985 ; Mfouka, 1993, 1994, 1995)- est actif dans une situation de relatives imprécision, indétermination et incertitude. C'est pourquoi l'économie comportementale insiste sur les biais de la décision, qui peuvent être aussi des biais culturels. La culture, disposition stabilisante d'interaction, peut donc être inadéquate.

Pour comprendre les dispositions régulières de l'agent et de l'interaction socio-économiques, il devient primordial de comprendre la culture de la situation d'existence et ses incidences sur la personnalité, les attitudes et les comportements des individus. L'économie et la gestion de la situation d'existence en dépend, notamment le développement socioéconomique. C'est l'intérêt de ce travail. D'où la problématique suivante : qu'est-ce que la culture et comment particularise-t-elle l'agent économique national ? Pour illustrer cette problématique dans le cas du Congo-Brazzaville, on rajoute la question suivante : quelles sont les grandes caractéristiques de la culture et de l'acteur socio-économique congolais ? On répond à ces questions en deux parties. Dans la première partie, on clarifie l'approche de la culture. On situe la culture dans un cadre organisationnel national où la culture est incarnée par une personnalité de base, relativement représentative de l'acteur socio-économique congolais. On propose et on justifie théoriquement une série d'hypothèses sur la culture du Congo-Brazzaville. Dans la seconde partie, on structure des hypothèses que l'on vérifie dans une enquête. Après avoir présenté les résultats statistiques, on les interprète et on en tire quelques conclusions.

L'objectif de ce travail est de mettre en évidence un modèle d'attitudes et de comportements communs à des acteurs ayant vécu durablement dans une même situation. Au niveau méthodologique, on admet que la culture est 
d'abord une perception régulière ou des régularités d'une réalité qui se traduit par une conviction. Cette conviction -relativement objective ou subjective, rationnelle ou irrationnelle- dispose les acteurs dans leurs approches, anticipations et interactions. Donc les hypothèses proposées et testées dans l'échantillon sont d'abord des convictions forgées par l'expérience et confirmées par d'autres analyses ou études. Les hypothèses portent généralement sur la rationalité, la subjectivité, la déviance, le bien-être, la liberté d'expression et l'État de droit, le service public, la cohésion et l'intégration sociale. Ces hypothèses sont détaillées dans un questionnaire (cf. Annexe 1) en différents thèmes présentés sous forme de propositions sur lesquelles les individus de l'échantillon se prononcent. Au niveau des perspectives de choix, les propositions sont fermées. L'échantillon est constitué d'adultes titulaires d'un baccalauréat, choisis au hasard. Il s'agit donc d'une population instruite. Les résultats statistiques sont présentés dans des tableaux (cf. Annexe 2).

\section{1- Culture, organisation socio-économique et personnalité de base \\ 1.1- Approche de la culture}

La culture est un ensemble de connaissances, de valeurs ou d'éléments symboliques ou matériels cohérents d'une société, de manières, d'activités et d'institutions (Echaudemaison, 1993 ; Durand \& Weil, 2006). La culture peut être individuelle ou collective (Journet, 2002). Au niveau social, la culture est surtout partagée et favorable à la communication. Pour Selznick $(1949,1957)$, elle est une disposition de lien social. Ce lien définit une relation d'appartenance et d'adhésion à des normes et des valeurs. La culture confère au groupe une identité et un langage de communication (Olayinka et al., 2018). Pour l'anthropologie (Morin, 2010), la culture est un modèle de comportement ou de manières habituelles issues d'activités apprises et transmises (Durand \& Weil, 2006, p.354). La manière générale de se présenter et d'agir correspond par exemple au mode de vie (Lendrevie \& Lindon, 2000). À partir de la proximité de comportements, d'opinions et de valeurs, on peut définir des styles de vie (Ibid). Le mode ou le style de vie aide à constituer des catégories ou groupes d'individus culturellement proches, à définir le positionnement de l'entreprise sur le marché ou à définir des segments de clientèle (Lebailly \& Bernabia, 2011; Dubois, 1987). La culture permet de définir des identités. La culture ou l'identité culturelle expliquent l'attitude ou le comportement (Marchand, 2009; Fitton, 2017). En tant que modes de pensée, de décision et d'action communs à un groupe de personnes (Ibid. ; Hounounou, 2005), la culture se rapproche de la civilisation. La civilisation, de nature supranationale, a une dimension morale. La culture est souvent restreinte à la nation ou à des groupes réduits. L'approche anglo-saxonne unifie la culture et la civilisation en les décrivant à partir de la connaissance, 
la croyance, l'art, la morale, le droit, la coutume, les capacités et habitudes acquises (Durand \& Weil, 2006).

Le culturalisme explique les actions humaines par un conditionnement culturel qui rend possible l'apprentissage et l'adoption d'un modèle commun d'attitudes et de comportements. L'approche fonctionnaliste confère à la culture un rôle instrumental de satisfaction de besoin et de résolution de problèmes. L'approche institutionnelle lui confère un rôle intégrateur de cohésion de l'organisme social. La culture est issue de l'habitus, c'est-à-dire des habitudes et des attitudes acquises qui s'érigent en disposition d'orientation ou de référence. Cet habitus résulte de la socialisation et de l'interaction dans la situation d'existence (Hounounou, 2005 ; Durand \& Weil, 2006). Il en découle un capital humain qui permet aux acteurs d'occuper des positions ou rôles définis dans le cadre de statuts et normes sociaux (Ibid.). La culture devient un construit évolutif et un système de régulation sociale, donc d'économie et de gestion des attitudes et des comportements.

La culture est relativement explicite ou implicite. Il y a deux niveaux d'aspects relativement explicites de la culture (Meier, 2010) qui vont retenir notre attention :

- le niveau extériorisé des règles, procédures, pratiques et comportements usuels,

- le niveau intériorisé des croyances, valeurs et normes.

Si ces deux niveaux sont à la base de l'organisation, le second est très institutionnel.

\section{2- De la culture à l'organisation et la personnalité de base nationales}

Dans l'approche socio-culturelle de l'acteur, le groupe semble plus important que l'individu puisque la culture commune est transmise et préservée dans une collectivité (Facchini, 2008). Le niveau intériorisé de la culture forge les attitudes communes du groupe. Le niveau extériorisé homogénéise les comportements. Ces deux niveaux sont justifiés ou légitimés par une certaine logique plus ou moins rationnelle.

\subsection{1- La culture, la personnalité de base et l'agent économique}

La culture est une disposition de cohérence dans la société à travers l'organisation sociale et l'interaction qu'elle canalise à travers les décisions et actions individuelles ou collectives. Au sein de l'organisation sociale, l'interaction est guidée par des croyances, des valeurs et des normes communément admises. Elle est soumise à des règles et des procédures, des pratiques et des comportements acceptables. Elle est aussi influencée par d'autres éléments observables de la culture (Meier, 2010 ; Strategor, 2005) tels que les tabous et interdits, l'histoire, le métier, le référentiel de développement, 
le positionnement dans l'environnement, l'identité et les signes distinctifs d'appartenance, le processus de décision ou le management et la source de pouvoir. La référence sociale de l'interaction devient un filtre d'attitudes et de comportements qui contraint la liberté individuelle. L'acteur socioéconomique est alors jugé socialement sur la base d'une personnalité dite de base (Kardiner, 1969 ; Linton, 1968). Cette personnalité est sociale (Dufrenne, 1972). Elle résulte de la culture et, en particulier, des institutions primaires (comme la famille ou les petits groupes) et des valeurs dominantes. Cette personnalité est une référence des attentes sur les rôles socio-économiques (appris ou espérés) qui affectent les attitudes et comportements des acteurs. L'acteur décide et agit donc en fonction d'un modèle culturel -appris ou imitéde la personnalité. La personnalité de base incarne ce modèle social d'attitudes et de comportements généralement attendus de tout agent membre d'une société. Elle est une mémoire active de la culture. Il y a des similitudes et des nuances dans les modèles culturels humains (Guimond, 2010).

La personnalité de base n'explique pas tous les attitudes et comportements de l'agent économique. Il convient aussi de tenir compte de la situation d'interaction et de l'habitus individuel (Boudon, 2012), c'est-à-dire des dispositions psychiques qui orientent ou encadrent les attitudes et le comportement spécifique de l'individu. La personnalité propre issue de cet habitus peut remettre en question la personnalité sociale. Ainsi Stien (2012) décrit l'acteur à partir de la personnalité (caractéristiques individuelles), la culture (caractéristiques de l'environnement social) et la dimension humaine universelle (caractéristiques communes à tous les humains).

\subsection{2- La nation comme une structure d'organisations culturelle}

Dans l'approche d'économie et de gestion, la nation est une organisation culturelle représentée par une personnalité nationale de base des acteurs socioéconomiques. Cet espace est géré par un État et des collectivités publiques à travers des institutions et des organisations publiques ou affiliées. Il est aussi sous l'influence d'autres acteurs individuels ou collectifs, institutions et organisations socioéconomiques.

\subsubsection{1-Personnalité de base, organisation culturelle et perspective d'interaction}

L'organisation culturelle est un espace d'interaction fondée sur la référence partagée de la personnalité de base. Les acteurs en interaction communiquent et échangent en partant de cette référence qui devient une valeur ultime. Cette valeur, en générant des attitudes et des comportements partagés, explique aussi la valeur économique de la nation. On ne peut plus détacher la valeur économique de la valeur sociale ou culturelle. La personnalité de base permet de caractériser l'acteur socioéconomique national. 
Ce dernier devient une entité située dans une culture qu'il exprime relativement à travers la personnalité de base, au cours de l'interaction (Schutz, 1987 ; Plane, 2003). Dans une perspective de décision et d'action, on peut caractériser la personnalité de base par des institutions, des représentations, des motivations, des ressources disponibles, le potentiel d'organisation et de résolution de problèmes. Les institutions sont des références des représentations. Les représentations sont des dispositions de communication dans l'espace national. Elles structurent les échanges. Issues des représentations, les motivations déterminent la décision. La mise en œuvre des décisions exige la disponibilité des ressources, un potentiel d'organisation et de résolution de problèmes.

\subsubsection{2-Organisation nationale et développement}

On peut analyser l'organisation nationale comme une structure d'organisations institutionnelles et non institutionnelles. L'organisation institutionnelle incarne les institutions au sens politique ou sociologique. Elle produit la culture intériorisée à travers des acteurs -de gouvernance, de référence ou d'orientation- comme l'État, les collectivités, la religion, la famille. Ces acteurs d'intégration sociale sont impliqués dans les questions de socialisation et de gestion de la nation. L'organisation institutionnelle est censée être une référence de régulation des institutions. Elle est censée faire la promotion de valeurs, normes ou modèles favorables à l'épanouissement, au développement et au bien-être des populations dans la nation. Elle devrait susciter des opportunités ou orienter les agents vers des opportunités de réalisation de leurs aspirations, dans une situation favorable. L'organisation non institutionnelle a un autre objet. Elle est souvent impliquée dans la satisfaction des besoins divers. Dans l'exercice de sa mission ou de sa vocation particulière, elle se conforme surtout aux institutions publiques.

La structure et le fonctionnement de l'organisation globale de la nation contribuent à la dynamique qui influence la trajectoire de développement politique, culturel, social et économique. Au niveau politique, concernant en particulier la gestion par l'État de la société civile, le développement correspond à une institutionnalisation réussie sur les dimensions de l'intégration et de la maîtrise des tensions et conflits, de la participation et de la répartition des ressources, de la stabilité des structures et des valeurs communes (Coleman, 1965). Au niveau économique, il se traduit par l'amélioration des facteurs de production, des combinaisons productives, des rendements et de la qualité du système de production. Le développement social élève le niveau de vie et de satisfaction des besoins (Lê Thành, 1984). Il est fondé sur un développement culturel, donc sur des connaissances, valeurs et attitudes favorables à l'épanouissement des personnalités et de leurs capacités créatrices (Ibid.). 
Si l'institution est inadaptée et les organisations constitutives défaillantes, l'organisation nationale inadéquate ne peut relever les défis du développement et de l'intégration de la nation dans l'économie mondiale.

\section{2- $\quad$ Enquête et analyse de l'enquête sur la culture congolaise \\ 2.1- Hypothèses et enquête sur la culture}

Il est possible d'évaluer la culture d'une société ou la personnalité d'un individu (Schwartz, 2006 ; Stien, 1012). Dans ce travail, l'évaluation a été faite à partir d'une enquête sur le ressenti ou le vécu individuel de la culture. Cette enquête met en évidence ce que les individus de l'échantillon retenu pensent ou constatent au sujet de la culture congolaise. On analyse la culture congolaise à partir de certains traits caractéristiques que l'on suppose être prédominants. On retient les dimensions culturelles suivantes proposées par Hofstede (1982) et Trompenaars (1993) : l'importance de la distance hiérarchique -entre subordonné et supérieur- ou les inégalités admises, la relation individualiste ou communautaire, la relation à l'incertitude et à l'ambiguité, l'objectivité ou la subjectivité, la discontinuité ou la continuité entre vie privée et vie professionnelle, l'orientation féminine ou masculine des valeurs, le mode d'acquisition du statut, la conception du temps. L'orientation masculine admet le conflit et met l'accent sur l'ambition (la réussite et la possession), la recherche d'efficacité et d'efficience. L'orientation féminine insiste sur la cohésion sociale, la qualité de la vie et la prévention des conflits. La relation à l'ambiguîté ou à l'incertitude décrit aussi la volonté ou le refus de contrôler la nature.

L'enquête menée en Janvier 2020 porte sur un échantillon de 125 individus adultes détenteurs d'un baccalauréat. Ce niveau d'instruction est favorable à une meilleure compréhension des problématiques de l'enquête. Il peut aussi aider à prendre du recul par rapport à certaines traditions ou coutumes. Les différents aspects de la culture retenus sont résumés dans les thèmes suivants (cf. Annexe 2) : les croyances, la famille, le pouvoir ou l'autorité, la résolution des problèmes, la distraction ou les loisirs, les rapports humains, la libre expression, l'activité économique, la mort, la santé, la formation et le bonheur. Chaque thème $\mathrm{T}_{\mathrm{i}}(\mathrm{i}=1,2, \ldots, 10)$ contient des propositions $\mathrm{P}_{\mathrm{ij}}(\mathrm{j}=1,2, \ldots 11)$. Les individus sondés se sont exprimés en fonction de leur conviction profonde ou de leur perception de la réalité de la société congolaise.

\section{2- Résultats de l'enquête}

\subsection{1- Résultats sur le mysticisme, la solidarité, le pouvoir et la résolution des problèmes}

Le thème $\mathrm{T}_{1}$ porte sur le mysticisme, notamment sur l'existence de Dieu et des esprits $\left(\mathrm{P}_{11}\right)$ et sur la réalité de la sorcellerie, du fétichisme et de 
l'envoûtement $\left(\mathrm{P}_{12}\right)$. Pour $98 \%$ de personnes sondées, le mysticisme fait partie des pratiques ou du mode de pensée des congolais. L'influence de Dieu et des esprits ou de l'occultisme est admise. Le thème $T_{2}$ concerne la solidarité : l'attachement à la famille $\left(\mathrm{P}_{21}\right.$ et $\left.\mathrm{P}_{22}\right)$ et la quête de mutuelles informelles $\left(\mathrm{P}_{23}\right)$ est admise par une moyenne de $86 \%$ de la population de l'échantillon. $92 \%$ est attaché à la famille, $76 \%$ pense que la famille est un lieu de solidarité et d'entraide et $89,6 \%$ estime que la quête de mutuelles informelles se répand de plus en plus.

Le thème $T_{3}$ porte sur le vécu ou le ressenti du pouvoir, de l'autorité et de la responsabilité incarnés par l'aîné $\left(\mathrm{P}_{31}\right)$, les forces armées ou de l'ordre $\left(\mathrm{P}_{32}\right)$ et le chef $\left(\mathrm{P}_{33}\right) .91,46 \%$ de la population admet les abus de pouvoir du chef, la responsabilité ou l'autorité incarnée par l'aîné et les forces armées ou de l'ordre. Pour $89,6 \%$ de la population, l'aîné incarne une autorité ou une responsabilité dans la famille. Pour $90,4 \%$, les forces armées ou de l'ordre incarnent un pouvoir ou une autorité au Congo. 94,4\% estime que le chef profite de sa position pour résoudre divers problèmes.

Le thème $\mathrm{T}_{4}$ traite de la résolution des problèmes sur la base de la transparence $\left(\mathrm{P}_{41}\right)$, du réseau d'influence $\left(\mathrm{P}_{42}\right)$ et de l'argent $\left(\mathrm{P}_{43}\right) .89,33 \%$ de la population admet l'opacité dans la résolution de problème et le besoin d'intermédiaires ou d'argent pour trouver des solutions. Pour $77,6 \%$ de la population, il est difficile de trouver la bonne information ou l'information officielle au Congo. 95,2\% de la population estime qu'il est nécessaire d'avoir de l'argent (pour corrompre) ou de s'appuyer sur un réseau de relations pour résoudre un problème au Congo.

\subsection{2- Loisir, discrimination ou inégalité et libertés}

Le thème $T_{5}$ traite des distractions et loisirs au Congo. Les individus sondés affirment que les distractions et loisirs portent -par ordre d'importancesur la boisson pour $84 \%$, la télévision pour $70,4 \%$, les paris et jeux de loterie pour $60 \%$. Ensuite viennent, pour près de $40 \%$ de la population, les jeux de société, le sexe, la musique, la causette et le sport. La danse n'est évoquée que par $22,4 \%$ de la population, la restauration par $11,2 \%$ et, la lecture, en dernière position, par 9,6\% de la population.

Le thème $\mathrm{T}_{6}$ concerne les rapports humains, notamment les inégalités et les discriminations qui sont admises en moyenne par $83,33 \%$ de la population. $61,6 \%$ pense que la femme est soumise à l'homme $\left(\mathrm{P}_{61}\right)$. Moins de $40 \%$ pense le contraire. $89,6 \%$ admet que l'homme travaille pour la femme et les enfants $\left(\mathrm{P}_{62}\right) .94,4 \%$ estime que la femme s'occupe du foyer et des enfants $\left(\mathrm{P}_{63}\right)$. Pour 93,6\%, les travaux ménagers sont le lot de la femme et des enfants $\left(\mathrm{P}_{64}\right) .71,2 \%$ estime que les enfants ne sont pas écoutés ou sont brimés $\left(\mathrm{P}_{65}\right)$. Une proportion de $24 \%$ pense le contraire. Enfin, pour $89,6 \%$, certains groupes tribaux sont victimes de discrimination $\left(\mathrm{P}_{66}\right)$. 
Le thème $T_{7}$ traite des institutions. Pour $94,4 \%$, l'absence de liberté d'expression et de démocratie effective va de pair avec le sentiment de peur ou de méfiance envers le système de gouvernance politique en place. Pour 96,8\% de la population, il n'y a ni liberté d'expression ni démocratie au Congo $\left(\mathrm{P}_{71}\right)$. Pour $92 \%$, le système de gouvernance politique en place inspire la méfiance ou la peur $\left(\mathrm{P}_{72}\right)$.

\subsection{3- L'économie, la santé, l'éducation et le bonheur au Congo}

Le thème $\mathrm{T}_{8}$ porte sur l'économie. Les différents aspects traités sont : le rapport au temps $\left(\mathrm{P}_{81}\right)$, l'emploi et les réseaux ou la corruption $\left(\mathrm{P}_{82}\right.$ et $\left.\mathrm{P}_{83}\right)$, la présence étrangère dans le commerce formel $\left(\mathrm{P}_{84}\right)$, l'initiative et les chances de succès au Congo $\left(\mathrm{P}_{85}, \mathrm{P}_{86}\right.$ et $\left.\mathrm{P}_{87}\right)$, le désir d'immigration $\left(\mathrm{P}_{88}\right)$, l'activité favorite des congolais pour l'entrepreneuriat $\left(\mathrm{P}_{89}\right)$, l'État-Providence $\left(\mathrm{P}_{810}\right)$ et la qualité des biens et services $\left(\mathrm{P}_{811}\right)$. Pour 93,6\% de la population, le congolais n'est pas rigoureux sur la notion de temps $\left(\mathrm{P}_{81}\right) .73,6 \%$ ne sait pas où chercher et espérer trouver du travail $\left(\mathrm{P}_{82}\right)$. Ils sont $96 \%$ à penser qu'il faut de l'argent ou des relations pour être embauché $\left(\mathrm{P}_{83}\right)$. Selon $94,4 \%$ des sondés, le commerce formel est souvent tenu par un étranger $\left(\mathrm{P}_{84}\right) .47,2 \%$ pense qu'il n'est pas possible d'entreprendre et de réussir au Congo, contre 49,6\% ( $\left.\mathrm{P}_{85}\right)$. $\mathrm{Si}$ une proportion de $88 \%$ espère néanmoins créer sa propre activité $\left(\mathrm{P}_{86}\right)$, seulement $52,8 \%$ pense qu'il y a des chances de réussite professionnelle contre $45,6 \%\left(\mathrm{P}_{87}\right)$. Pour $72,8 \%$ de la population, mieux vaut immigrer $\left(\mathrm{P}_{88}\right)$; seulement $24 \%$ pense le contraire. Au niveau de l'entrepreneuriat, $96 \%$ estime que les congolais entreprennent souvent dans la vente de boisson $\left(\mathrm{P}_{89}\right)$. Pour $88 \%$, l'État ou le service public ne travaille pas à l'amélioration de la vie des populations $\left(\mathrm{P}_{810}\right)$. Pour $83,2 \%$, la question de la satisfaction des usagers ou des clients importe peu au Congo $\left(\mathrm{P}_{811}\right)$.

Le thème $\mathrm{T}_{9}$ porte sur la mort : l'augmentation du taux de mortalité $\left(\mathrm{P}_{91}\right)$, la menace que constitue la sorcellerie $\left(\mathrm{P}_{92}\right)$, la mobilisation des ressources pour la mort au lieu de la santé $\left(\mathrm{P}_{92}\right)$ sont admises par $96,8 \%$ des individus en moyenne. 96\% admet que la sorcellerie est une menace. Pour $97,6 \%$, le congolais dépense plus pour enterrer le mort que pour soigner le vivant. Le thème $\mathrm{T}_{10}$ traite du capital humain et du bien-être : la santé $\left(\mathrm{P}_{101}\right)$, la formation $\left(\mathrm{P}_{102}\right)$, le bonheur au Congo $\left(\mathrm{P}_{103}\right)$ et les anticipations sur l'avenir $\left(\mathrm{P}_{104}\right)$ ). Pour $72,26 \%$ de la population en moyenne, les malades ne sont pas bien soignés, il n'y a pas de bonnes formations et on n'est pas heureux de vivre au Congo. Ils sont $96 \%$ à déplorer le système de santé et $61,6 \%$ le système de formation. $59,2 \%$ de la population (de l'échantillon) n'est pas heureux de vivre au Congo contre 40\%. 52,8\% est tout de même optimiste contre 46,4\%. 


\section{3- Conclusions sur l'enquête et la personnalité de base du congolais}

2.3.1- Le poids des traditions à travers le mysticisme, la solidarité et les discriminations

L'enquête confirme l'hypothèse du mysticisme dans la pensée congolaise. Cette pensée accorde une grande place à Dieu, aux esprits, à la sorcellerie, au fétichisme et à l'occultisme. La sorcellerie est considérée comme une menace. Le mysticisme est lié à la place de la religion, des coutumes et traditions ancestrales dans la société. Il est propice par exemple à l'irrationalité, la subjectivité, la peur, aux préjugés, aux stéréotypes et au refus de contrôler la nature. Il dénote une certaine aversion pour le risque compatible avec une sorte d'inhibition -face à la complexité ou à l'ambiguïté- qui empêche l'initiative. L'instruction des individus de l'échantillon ne remet nullement en question l'influence du mysticisme. L'expansion de l'évangélisme et l'afflux de populations immigrées musulmanes pratiquantes (d'Afrique de l'Ouest) ne peut qu'accentuer ce phénomène.

L'enquête met en évidence l'attachement à la famille (lieu de solidarité) et la quête de solidarité. L'opinion de l'échantillon révèle une société congolaise caractérisée par des inégalités et des discriminations. Le mâle paraît très dominant au Congo-Brazzaville, surtout dans la famille. Le modèle familial est patriarcal. L'homme est censé incarner l'autorité et le pouvoir matériel et financier dans la famille. La famille ne semble pas être un lieu d'interaction équilibré entre l'homme, la femme et les enfants. La famille élargie est le terrain où règne surtout l'aîné. La discrimination est accentuée par la solidarité tribale et familiale qui est un fondement de la relation sociale et des réseaux d'influence. Ce modèle est certainement en perte de vitesse avec le chômage croissant des hommes, l'activité croissante des femmes très présentes dans le secteur informel, l'éclatement des clans et familles élargies, le brassage des tribus... En outre, la pauvreté réduit les ressources mobilisables pour la solidarité.

\subsection{2- Un contexte social défavorable à la confiance et à l'initiative organisée}

Les résultats confirment la continuité entre vie professionnelle et vie privée assurée par les réseaux et la déviance à travers l'instrumentalisation, la manipulation et le détournement des institutions et des organisations et le rapport de force. Ils révèlent des phénomènes d'opacité dans les interactions, de défaillances et d'asymétrie de l'information et l'influence des réseaux relationnels dans la résolution des problèmes. L'absence de transparence ne peut qu'accentuer les phénomènes de rumeur et de déviance. L'enquête confirme l'influence des forces armées ou de l'ordre et le ressenti d'abus de pouvoir à différents niveaux de la société. Il ressort de l'échantillon que le Congo n'est pas un pays de liberté, mais de la contrainte, de la méfiance ou 
de la peur; ce qui va de pair avec l'absence effective de liberté d'expression ou de démocratie. L'enquête confirme la pensée selon laquelle il est difficile de résoudre un problème au Congo en suivant une procédure normale, avec une bonne information, sans besoin d'intermédiaire ni de corruption.

Tout ce contexte est favorable aux dysfonctions et à l'inefficacité des organisations au niveau national. Propice à la méfiance, il est aussi défavorable à la communication, la décision et la négociation.

\subsection{3- L'activité et le bien-être}

Il ressort des résultats de l'enquête (cf. 2.2.3) que les congolais ne sont pas rigoureux sur le temps. L'activité n'est pas définie dans un cadre temporel strict. Dans ce contexte, les notions de planification, de programmation ou de projet et de développement posent problème. Trouver du travail ou créer son entreprise semble poser problème au Congo. La perspective du travail est perçue comme floue ou bouchée, soumise à la corruption et aux relations d'influence. Le marché du travail apparaît opaque. Le poids de la relation et de l'argent ressenti dans la recherche d'emploi confirme l'influence des comportements déviants dans la résolution de problèmes. Les difficultés d'emploi contraignent à l'entrepreneuriat. Alors que pour le congolais, l'entrepreneuriat ne semble surtout possible que dans l'informel, l'étranger est dominant dans le commerce formel, sauf dans les débits ou la vente de boissons. Il faut souligner que la boisson alcoolisée est aussi l'un des rares secteurs dans lequel les commerçants ouest-africains, souvent musulmans, n'osent pas s'aventurer, par respect pour l'Islam. Au sujet même du succès de l'entrepreneuriat ou de la réussite professionnelle, l'optimisme et le pessimisme sont presqu'au même niveau.

Les loisirs mis en avant ne favorisent pas l'épanouissement de l'individu. Ils sont plutôt propices à la passivité (télévision) ou aux addictions (boissons alcoolisées, paris et jeux de société). Le congolais semble très éloigné de la lecture et peu intéressé par la pratique du sport. Le système de santé et de formation au Congo est remis en question dans l'enquête. Le ressenti ou le vécu de l'échantillon montre que le congolais est de plus en plus confronté à la mort. Déjà pauvre, il mobilise de plus en plus de ressource pour honorer le mort que pour soigner le vivant. Le service ou le secteur public n'est pas reconnu pour la qualité de ses biens et services. Le congolais ne croit pas dans l'État-providence. L'État ou le service public ne donne pas l'impression de se préoccuper de l'amélioration de la vie des populations. Finalement, une majorité d'individus n'est pas heureuse de vivre au Congo et envisage l'immigration comme solution. 


\section{4- Confirmation des hypothèses par d'autres analyses et données}

\subsection{1- Les traditions, le sous-développement, la pauvreté et les inégalités}

Le schéma culturel du Congo-Brazzaville est bien conforme au modèle africain (Meier, 2010) proposé par Etounga Manguelle (1991). Ce modèle s'appuie sur la famille, les traditions, la solidarité, la religion, le culte du chef, le respect et la loyauté, les croyances, mythes, histoires, symboles et rites. Hugon (1993) explique l'irrationalité de l'homo africanus par l'influence des réseaux familiaux, des structures sociales et du système de valeurs. Dans ce contexte, Hyden (2007) parle d'économie affective caractérisée par une entente réciproque fondée sur la parenté, l'origine et la religion. Cette économie s'inscrit dans une logique communautaire dans laquelle la solidarité est un réducteur d'incertitude. Une part de cette incertitude s'explique par le sous-développement et la pauvreté. Ce problème est économique et social. L'économie en tant que représentations, pratiques et manières -de créer de la valeur- est aussi une culture. C'est sur la base de cette culture que les acteurs locaux prennent des initiatives plus ou moins responsables d'épargne, d'investissement, de production, de distribution et de consommation, avec plus ou moins de précaution. Les résultats de ces initiatives sont donnés par des indicateurs économiques.

On constate encore en 2020 que le Congo a toujours une économie de rente focalisée sur le pétrole (tresor.economie.gouv.fr). Le principal produit d'exportation du Congo est le pétrole brut (89\%). De 2018 à 2019, les exportations du Congo ont chuté de $-46 \%$, passant de 5405 milliards de F CFA (dont 4000 pour le pétrole) à 2904 milliards (dont 2584 pour le pétrole). Le bois représente $6 \%$ des exportations et le cuivre $1,7 \%$. Les exportations vers l'Afrique ne représentent que $1,32 \%$ en 2019. Les importations ont chuté de 1198 à 1108 milliards de F CFA. Le Congo importe surtout les produits agricoles et agroalimentaires (viandes, poissons et céréales), les «huiles de pétrole ou de minéraux bitumineux» puis les médicaments. Le tableau suivant des importations et exportations (de 2016 à 2019) montre une croissance des exportations de 2016 à 2018 et une baisse continue des importations de 2016 à 2019.

\begin{tabular}{|l|l|l|l|l|}
\hline & 2016 & 2017 & 2018 & 2019 \\
\hline Exportations & 1038 & 2428 & 5405 & 2904 \\
\hline Importations & 2798 & 1534 & 1198 & 1108 \\
\hline
\end{tabular}

Source INS (cf. tresor.economie.gouv.fr).

Une certaine baisse du pouvoir d'achat se reflète dans cette baisse des importations. Le secteur informel représente 70 à $80 \%$ de l'activité intérieure du Congo. La croissance hors pétrole était négative ou inférieure à $1 \%$ en 
2020. De nombreux secteurs économiques sont en difficulté à cause de crises successives depuis 2014. La croissance de l'activité a stagné en 2019, se fixant au niveau de $-0,6 \%$. Le FMI prévoyait une baisse du Produit Intérieur Brut (PIB) de $-7 \%$ pour 2020. Dès 2020, le gouvernement s'attendait à une baisse de la demande intérieure de $-41 \%$. Le secteur non pétrolier se serait dégradé de $11 \%$ en 2020 d'après la Banque Africaine de Développement (afdb.org.fr). Pour 2021, le déficit du solde budgétaire est estimé à 104 milliards de F CFA (1,7\% du PIB). Deux facteurs fragilisent le tissu productif local :

- l'arrêt du programme du FMI à cause de la dette (accumulation d'arriérés de paiement de l'Etat) et des problèmes de gouvernance,

- la dette commerciale intérieure publique.

Si l'économie est le reflet d'une culture, alors l'économie congolaise reflète bien une culture du sous-développement. Elle est peu diversifiée, enracinée dans les secteurs primaire et informel, dépendante de l'étranger, insuffisante pour nourrir la population, peu intégrée à l'économie sousrégionale ou mondiale, vulnérable aux variations de prix des matières premières, compatible avec la pauvreté et les inégalités. Finalement, la croissance a été négative de 2016 à 2019 : -2,8 en 2016, -3,1 en 2017, -3,4 en 2018 et -3,5 en 2019 (Groupe Banque mondiale, 2018 ; worldbank.org). Les chiffres de la Coface (coface.com) indiquent $-6,2 \%$ en 2018 et $-8 \%$ en 2020. L'extrême pauvreté a augmenté à partir de 2016. Le chômage était alors à $30 \%$ chez les jeunes de 15 à 29 ans, le taux de mortalité infantile de 33 pour 1000 naissances et celui de la mortalité maternelle de 442 pour 100000 naissances (Matamona \& Ndungu, 2018). D'après la Banque mondiale, 5\% des enfants du Congo n'atteindront pas leur $5^{\text {ème }}$ année et $21 \%$ des enfants souffrent de malnutrition chronique. Le Congo est un pays situé dans la tranche inférieure des pays à revenu intermédiaire. Son Produit Intérieur Brut (PIB) est de 9,7 milliards d'euros, soit un PIB par habitant de 1827 euros. Le classement selon l'indice de développement humain (IDH=0,608) plaçait le Congo à la $137^{\text {ème }}$ place sur 189 en 2018 et à la $138^{\text {ème }}$ place en 2019 (tresor.economie.gouv.fr et undp.org). Le taux de pauvreté varie de $43 \%$ en 2019 (undp.org) à 35\% en 2020 (Tresor.economie.gouv.fr). Si pour la Banque Africaine de Développement (BAD) la pauvreté touche 40,9\% de la population (www.afdb.org), le Trésor français avance le chiffre de 35\% (tresor.economie.gouv.fr). La pauvreté s'accompagne d'inégalités ou de discriminations : en 2019, la Banque mondiale estime que $65 \%$ des congolais les plus pauvres vivent dans les 6 régions du sud du pays et, moins de 4,9\% d'entre eux ont une protection sociale. Le chômage se situerait à 10,4\% selon l'estimation de la Banque mondiale en 2019. La Banque Africaine de Développement (www.afdb.org) confirme les inégalités de revenu, l'inadéquation entre formation et besoins du marché de l'emploi (faiblesse de 
l'offre de l'enseignement technique et professionnelle). À propos des inégalités, le coefficient de Gini est estimé à 0,46 (tresor.economie.gouv.fr). Le niveau de pauvreté a augmenté avec la pandémie du coronavirus.

\subsection{2- La déviance et les failles dans la gouvernance}

Le phénomène de corruption au Congo est reconnu par le gouvernement et le FMI dans un rapport sur la corruption (République du Congo, 2018). Le rapport admet qu'en 2016, le baromètre mondial de la corruption (Transparency International) plaçait le Congo au $159^{\text {ème }}$ rang sur (176). Il souligne que «75,2\% des entreprises congolaises interrogées s'attendaient à donner des cadeaux en échange de marchés publics et $81,8 \%$ s'attendaient à récompenser des fonctionnaires de l'État pour que le travail soit fait» (Ibid., p.27, 1.22-24). Le rapport note des failles au sujet de la gouvernance, la transparence et la corruption. Le rapport sur la corruption reconnaît par exemple que des « faiblesses au niveau de la transparence et dans les systèmes de contrôle des dépenses ont contribué à l'augmentation considérable de l'encours de la dette (de 20\% du PIB en 2010 à $119 \%$ du PIB en 2017)» (Ibid., p.5, 1.18-20). Le chaos institutionnel, les inégalités et la marginalisation politico-socio-économique du citoyen y sont confirmés par « la faiblesse des institutions et de conditions équitables de participation au processus de création de richesses» (Ibid., p.5, 1.28-29). L'opacité et l'asymétrie d'information sont également reconnues car le rapport précise bien que « le système de gouvernance du pays souffre d'un déficit au niveau de la transparence et de la communication d'informations et de données au public » (Ibid., p.5, 1.9-11). En 10 ans de lutte contre la corruption, aucun dossier n'a été traité par la justice. Le cadre légal et réglementaire n'est pas appliqué. Le rapport note des insuffisances dans l'État de droit, donc la marginalité de la justice. Le rapport reconnaît que la gouvernance au Congo s'investit peu dans la lutte contre la corruption. D'après la Banque mondiale (cf. site banquemondiale.org), le Congo, classé $180^{\text {ème }}$ sur 190 dans le rapport « Doing Business » a intérêt à améliorer sa gouvernance. Au niveau des critères -de droit, de l'efficacité de la réglementation, de l'ouverture des marchés et du rôle de l'Etat- évalués à travers l'indice de liberté économique, le Congo est $46^{\text {ème }}$ dans sa région et $176^{\mathrm{ème}}$ dans le monde (cf. objectif-import-export.fr et fellah-trade.com). Cette position confirme les obstacles à la liberté d'initiative.

\section{5- Analyse des conséquences des résultats de l'enquête et de la corruption au Congo}

\subsection{1- Exploitation du rapport social et influence des réseaux dans la culture étudiée}

Le rapport sur la corruption (Ibid) montre qu'au Congo, certaines organisations ou institutions publiques sont gangrenées par la corruption. 
Cette corruption est un aspect de la relation sociale qui structure des réseaux d'intérêts divers, variés, partagés ou convergents. Le réseau ne peut être un outil de corruption que parce que certains individus qui le constituent ont une capacité relationnelle ou un potentiel de pouvoir et de déviance. Cette capacité et ce potentiel participent aux abus qui fragilisent les organisations ou les institutions publiques et leur rationalité. En effet, sans loyalisme ni conformité, il n'y a plus de corps communautaire (Parsons, 1973). La situation s'empire si l'autorité elle-même devient déviante. Pourquoi, en effet, procèderait-elle à un contrôle de validité qui la mettrait en cause ? Lorsque des réseaux de déviance se développent, se développent aussi des relations biaisées qui échappent aux principes rationnels d'économie et de gestion : des dysfonctions apparaissent dans l'organisation sociale (Merton, 1965). Pour Goffman (1968), l'incertitude ou la pression (qui peut être due aux conditions difficiles de vie ou à la pauvreté) conduit vers une adaptation secondaire, c'està-dire vers des dispositions habituelles permettant l'utilisation de moyens défendus, la manipulation ou le détournement des normes ou prétentions de l'organisation ou de la personnalité.

Les résultats de l'enquête montrent aussi qu'au Congo, la relation sociale est impactée par des coutumes et traditions fortement subjectives et irrationnelles. Il en découle des préjugés, des stéréotypes et des peurs difficiles à justifier (Meier, 2010). La marginalité de la justice au sujet de la corruption, donc l'impunité, le leadership inné de l'aîné masculin qui n'a pas à prouver ses capacités de gestion de groupes humains viennent confirmer le lot d'irrationalité que véhicule la culture du Congo Brazzaville. Si les forces armées ou de l'ordre incarnent l'autorité comme le montrent les résultats de l'enquête, c'est que la force semble avoir une place importante dans la représentation du pouvoir, au lieu de la loi (comme le montre l'impunité dans le cas de corruption). Ce fait est confirmé par le règne de présidents issus de l'armée depuis 1968, soit 45 ans de règne sur 50. L'armée semble bien incarner un pouvoir comme le montre l'enquête.

\subsection{2- L'inefficacité institutionnelle et organisationnelle et la déviance}

L'organisation est un pouvoir par ses règles et ses structures (Plane, 2003). Logiquement, le poids de l'irrationalité et de la déviance associé à l'impunité (cf. 2.4 et 2.5.1) ne peut qu'accentuer l'effacement de la légitimité institutionnelle et de la conformité organisationnelle. En effet, le contournement, le détournement ou la marginalité des règles et procédures efficaces de contrôle et de qualité rompent la cohérence organisationnelle qui serait fondée sur l'efficacité et l'efficience. L'autorité en tant que droits accordés par l'organisation -à une position managériale- de donner des ordres à exécuter (Robbins \& Judge, 2006) disparaît. Le jeu organisationnel devient ambigu: les zones d'incertitude des acteurs s'accentuent (Crozier \& 
Friedberg, 1977). L'organisation n'est plus un nœud de contrats (Berle \& Means, 1932). N'étant plus canalisé par la référence organisationnelle, le contrat organisationnel n'étant plus effectif, le manager acquiert alors une certaine liberté individuelle favorable à l'opportunisme et à la déviance. Les anticipations sur l'interaction deviennent aléatoires ou irrationnelles. Déjà un contrat incomplet pose des problèmes d'opportunisme (Williamson, 1994 ; Jensen \& Meckling, 1976), combien plus une quasi absence ou ignorance du contrat.

Dans ce contexte de déviance et de corruption, le service public devient un réseau d'agents (de l'État, des collectivités et des entreprises publiques) intéressés par les usagers les plus attrayants ou les plus intéressants (au niveau de l'offre de privilèges, d'avantages, de relation sociale...). L'intérêt public disparaît au profit d'intérêts individuels ou de réseaux. Le concept d'ÉtatNation s'écroule. L'État tombe sous l'influence des réseaux et la nation devient un rassemblement de groupes ou systèmes culturels hétéroclites et conflictuels. Au sein de ces groupes ne peuvent que se développer des systèmes informels de pouvoirs autonomes ou de relais (de systèmes dominants). Dans ce contexte, l'opacité sert les abus.

\section{6- La personnalité de base du congolais}

La personnalité de base du congolais est enracinée dans la tradition ou la coutume et le chaos de la culture moderne (entretenu par une absence d'institutions claires et rationnellement légitimées, d'organisation rationnelle). Elle est potentiellement et socialement déviante, parasitaire de la relation sociale, irrationnelle, soumise, dépendante, peu encline au risque (donc peu entreprenante), pessimiste, démunie, déconnectée du temps, discriminée, marginalisée, attirée par des loisirs et distractions peu structurants pour le capital humain.

La culture moderne semble n'avoir produit ni des institutions dignes de confiance ni une organisation nationale favorable au développement. Cette situation chaotique semble plutôt propice à la non-conformité et au formalisme institutionnels et organisationnels, à l'illégalité ou l'illégitimité qui favorisent l'opportunisme et la relation sociale parasitée. Il s'en suit une irrationalité sociale. L'irrationalité collective des congolais résulte non pas seulement de la subjectivité inspirée par le mysticisme, mais aussi de ce chaos qui empêche la quête d'efficacité et d'efficience. Les abus de pouvoir, la soumission, les inégalités, les discriminations et les failles -dans la liberté d'expression, la démocratie et l'État de droit- accentuent l'irrationalité. Ayant l'impression d'être abandonné par l'État, concurrencé ou évincé par l'entrepreneur d'origine étrangère dans son propre pays, la déviance, l'immigration ou le mysticisme deviennent des solutions pour le congolais. La marginalité socioéconomique accroît la pauvreté. Naviguant souvent entre l'informel, le 
chômage et l'inactivité, le congolais se sent en marge de l'économie formelle ou de la sécurité sociale, soumis aux difficultés d'intégration socioéconomique. Le congolais travaille pour la satisfaction des besoins primaires. Il recherche une couverture sociale dans la solidarité informelle. Cette situation n'est favorable ni à l'optimisme ni au bien-être. Elle est plutôt angoissante. Globalement, la personnalité de base du congolais correspond à un capital humain inadapté à sa situation d'existence.

Tenant en outre peu compte du temps dans l'interaction, le congolais semble peu rigoureux dans la gestion des activités, peu ambitieux dans le besoin d'accomplissement, peu apte à apprécier la valeur économique de l'activité. Son temps libre est consacré aux activités addictives ou à la passivité.

\section{Conclusion}

La culture est un patrimoine social (œuvres intellectuelles et sociales) et un ensemble de connaissances, de manières (issues de pratiques), de valeurs et de symboles. Elle produit un modèle d'attitudes et de comportement qui se reflète dans un style ou un mode de vie, une civilisation. Ce modèle est mobilisé pour la résolution de problèmes, la satisfaction de besoin ou la cohésion sociale. La culture est un construit évolutif, plus ou moins explicite qui produit le capital humain. La nation est organisée autour d'une culture commune qui affecte la personnalité ou l'identité des acteurs socioéconomiques. La personnalité sociale, apprise dans la situation d'existence, attendue dans les interactions, est un modèle d'anticipation des attitudes et comportements des acteurs. La culture est distribuée à travers cette personnalité. L'enquête montre que la culture du Congo-Brazzaville est caractérisée par l'importance de la distance hiérarchique : le culte du chef, les abus de pouvoir et l'impunité. L'orientation communautaire de cette culture est traditionnelle mais aussi moderne. Elle est bien manifeste au niveau de la famille, du clan ou de la tribu, des réseaux ou de la relation d'influence. La mort ou le rapport à la nature, à l'incertitude, à l'ambiguïté, au risque ou à l'imprévisibilité sont souvent abordés en relation avec Dieu, les esprits, la sorcellerie ou le mysticisme. Par conséquent, la subjectivité et l'irrationalité sont des caractéristiques importantes de cette culture qui refuse tout contrôle de la nature. La continuité entre vie privée et professionnelle transparaît dans la relation sociale, les réseaux d'influence, les abus de pouvoir et la corruption qui gangrènent la vie des organisations. Si dans la culture traditionnelle le statut est attribué, les abus de pouvoir, la manipulation et le détournement des organisations ne peuvent que renforcer ce phénomène.

L'opacité, l'asymétrie d'information, l'absence de liberté d'expression et d'État de droit, l'irrationalité et la subjectivité, la fragilité du capital humain, des institutions et des organisations ne sont pas propices au bon 
fonctionnement des marchés, à la décision, à l'action, au développement. L'espace national est devenu un terrain d'apprentissage d'une culture qui combat la rationalité politico-socio-économique. Cette culture produit des difficultés de socialisation favorables à la marginalisation politico-socioéconomique des populations et à la déviance de la personnalité. Sur la base des résultats de l'échantillon, la personnalité de base du congolais, fondée sur la subjectivité, paraît irrationnelle, déviante, peu entreprenante, soumise ou dépendante, discriminée, en marge du temps, démunie, discriminée, encline aux loisirs addictifs. Elle est caractérisée globalement par un mal-être et un pessimisme. Étant en marge du cadre socio-économique formel, elle semble inadaptée pour relever les défis du développement et de l'intégration de la nation dans l'économie mondiale. La culture actuelle et la personnalité sociale qu'elle induit posent donc a priori problème pour l'avenir et le bien-être de la communauté nationale.

La subjectivité, voire l'irrationalité des réponses, ne remet pas en question les prédispositions majeures des sondés sur les thèmes de l'enquête. La personnalité sociale reste une base d'anticipation commune des attitudes et comportements. Mais, la culture ou la personnalité de base n'est pas le seul paramètre déterminant de l'interaction. Il convient aussi de tenir compte de la pression de la situation d'interaction et de la personnalité propre de chaque acteur, personnalité résultant de l'habitus individuel. Ayant mis l'accent sur les pesanteurs culturelles, il serait important de rechercher aussi les dispositions favorables à un changement culturel et au développement: la volonté d'entreprendre, l'optimisme d'une minorité non négligeable sur les chances de réussir au Congo et de celle qui se sent encore heureux d'y vivre. $\mathrm{Si}$ l'enquête confirme les hypothèses, certains aspects comme les discriminations, les structures socioéconomiques ou le bien-être devraient être approfondis en fonction de l'âge, du sexe des individus, de la catégorie socioprofessionnelle... Les traits de culture et de personnalité sociale analysés dans ce travail sont loin d'être exhaustifs ou parfaitement énoncés.

\section{References:}

1. ADEME (Agence de l'Environnement et de la Maîtrise de l'Énergie) (2016). Changer les comportements, faire évoluer les pratiques sociales vers plus de durabilité. L'apport des sciences humaines et sociales pour comprendre et agir, ADEME Éditions, Angers, France.

2. Barou V., Buridant G., \& Figliuzzi Montoussé, M. (2016). Histoire de faits économiques, Bréal, Lemesnil sur L'Estrée.

3. Baumol, W.J. (1990). «Entrepreneurship : productive, unproductive and destructive », Journal of Political Economy, vol. 98, n 5, pp. 893921. 
4. Becker, G. (1993). Human Capital: a theoretical and empirical analysis with special reference to education, The University of Chicago Press, National Barcan of Economic Research.

5. Berle, A.A. \& Means, G.C. (1932). The moderne corporation and private property, Mac Millan, New York.

6. Boudon, R., Besnard, P., Cherkaoui, M., Lécuyer, B.P. (2012). Dictionnaire de sociologie, Larousse, Paris.

7. Coleman, J. (1965). Education and political development, Princeton University Press.

8. Crozier, M., \& Friedberg, E. (1977). L'acteur et le système, Seuil, Paris.

9. Cuche, D. (2016). Notion de culture dans les sciences sociales, La découverte, Paris.

10. Dubois, B. (1987). «Culture et marketing », Recherche et Applications en Marketing, vol. 2, $\mathrm{n}^{\circ}$ 1, pp. 43-64.

11. Dufrenne, M. (1972). La personnalité de base, PUF, Paris.

12. Durand, J.P. \& Weil, R. (2006). Sociologie contemporaine, Vigot, Paris.

13. Echaudemaison, C.D. (1993). Dictionnaire d'économie et de sciences sociales, Nathan, Paris.

14. Etounga Manguelle, D. (1991). L'Afrique a-t-elle Besoin d'un Programme d'Ajustement Culturel ?, Les Éditions Nouvelles du Sud.

15. Facchini, F. (2008). «Culture, diversité culturelle et développement économique. Une mise en perspective critique de travaux récents », Revue Tiers Monde, 2008/3, $\mathrm{n}^{\circ}$ 195, pp.523-554.

16. Fitton, S. (2017). Le rôle explicatif des variables d'attitude et de personnalité dans les intentions de départ. Le cas des managers français, thèse de doctorat, Gestion et management, université de Bordeaux

17. Goffman, E. (1968). Asiles. Études sur la condition sociale des malades mentaux. Éditions de Minuit, Paris.

18. Guimond, S. (2010). «Le comportement social : similitudes et différences entre les cultures », dans Psychologie sociale : perspective multiculturelle, sous la direction de Guimond S., Wavre, Mardaga, pp.99-121.

19. Hofstede, G. (1982). Culture's Consequences, Sage Publications, Newbury Park.

20. Hounounou, A. (2005). 100 Fiches pour Comprendre l'Organisation et la gestion des Entreprises, Rosny, Bréal.

21. Hugon, P. (1993). «L'homo africanus est-il irrationnel ? Entretien avec P. Hugon », in Boutillier J.L. et Goudineau Y., Cahiers des 
Sciences Humaines: trente ans (1963-1992), Bondy, Montpellier (centre IRD), $\mathrm{n}^{\circ} \mathrm{h} \mathrm{s}, \mathrm{pp} .57-60$.

22. Hyden, G. (2007). « L'économie de l'afffection et l'économie morale dans une perspective comparative : qu'avons-nous appris ? », Revue du MAUSS, 2007/2 (n 30), pp.161-184.

23. Jensen, M.C., \& Meckling, W.H. (1976). «Theory of the firm : managerial behavior, agency cost and ownership structure », Journal of Financial Economics, 3, 4, pp.305-360.

24. Journet, N. (2002). La culture. De l'universel au particulier,Éditions Sciences humaines, collection « Synthèse », Auxerre, France.

25. Kahneman, D., Slovic, P., \& Tversky, A. (1982). Judjement under Uncertainty: heuristics and biasis, Cambridge University Press, Cambridge, Royaume Uni.

26. Kahneman, D., \& Tversky, A. (2000). Choices, values and Frames, Cambridge University Press, Cambridge, Royaume Uni.

27. Kardiner, A. (1969). L'individu dans sa société, Gallimard, Paris.

28. LaPorta, R., Lopez de Silanes, Shleifer, F., \& Vishni, R. (1999). «Quality of government», Journal of Law and Economics \& Organization, vol. $15, \mathrm{n}^{\circ} 1$, pp.222-279.

29. Lebailly, M. \& Benarbia, L. (2011). Le marketing culturel. Exploitez votre culture d'entreprise et transformez vos clients en adeptes, Pearson Éditeur, collection village mondial.

30. Lendrevie, J., \& Lindon, D. (2000). Mercator, Dalloz, Paris.

31. Lê Thành Khôi (1984). "Culture et développement", Revue Tiers Monde, 97, pp.9-28.

32. Linton, R. (1968). De l'homme, Editios de Minuit, Paris.

33. Marchand, R. (2009). Influences de la culture et de l'identité sur l'apprentissage $d u$ FLE: étude comparative des enseignements/apprentissages en France et en Chine, Thèse de doctorat, Université de Lorraine, Nancy 2.

34. Matamona, M. \& Ndungu, A.M. (2018). République du Congo. Perspectives Economiques en Afrique. Notes Pays (afdb.org).

35. Meier, O. (2010). Management interculturel. Stratégie, organisation, performance, Dunod, Paris.

36. Merton, R.K. (1965). Éléments de théorie et de méthode sociologique, Plon, $2^{\text {ème }}$ édition, Paris.

37. Mfouka, H.J. (1993). Modélisation des préférences imprécises et essai d'application à l'analyse multicritère, Thèse de doctorat, Université de Bourgogne, Dijon.

38. Mfouka, H.J. (1994). «De l'effet d'imprécision et du paradoxe de la non ponctualité des seuils vers la définition de quelques concepts et 
principes de modélisation des préférences », Document de travail du LATEC, $\mathrm{n}^{\circ}$ 9403, CNRS, Université de Bourgogne, Dijon.

39. Mfouka, H.J. (1996). «Des actions imprécises aux structures de préférence imprécises : cas des non-ordre », Document de travail $d u$ LATEC (URA 342 CNRS) $\mathrm{n}^{\circ}$ 9609, Juil.1996, Université de Bourgogne, Dijon.

40. Morin, J.M. (2010). La sociologie, Nathan, Paris.

41. Olayinka, A.S., Olufunke, A.O., \& Cole, A.O. (2018). « Symbols as Commemorative Emblems in Nigerian Film»European Scientific Journal, 14(2), 100. https://doi.org/10.19044/esj.2018.v14n2p100.

42. Parsons, T. (1973). Sociétés : Essai sur leur évolution comparée, Dunod, Paris.

43. Plane, J.M. (2003). Management des organisations. Théories, concepts, cas, Dunod, Paris.

44. Raffinot, M. (2015). Économie du développement, Dunod, Paris.

45. République du Congo (2018). Rapport sur la gouvernance et la corruption, 20 Juin 2018, rédigé en consultation avec les services du FMI, Ministère des finances et du budget.

46. Robbins, S., \& Judge, T. (2006). Comportement organisationnel, Pearson Education France

47. Roy, B. (1985). Méthodologie multicritère d'aide à la décision, Economica, Paris.

48. Schwartz, S.H. (2006). «Les valeurs de base de la personne : Théorie, mesure et application », Revue Française de Sociologie, vol. 47, ${ }^{\circ} 4$, pp.929-968.

49. Schutz, A. (1987). Le chercheur et le quotidien, Editions MéridiensKlincksieck.

50. Selznick, P. (1949). TVA and Grass Roots, University Of California Press, Berkeley.

51. Selznick, P. (1957). Leadership in Administration. A Sociological Interpretation, Harper \& Row, New York.

52. Sen, A. (1985). Commodities and capabilities, North Holland, Amsterdam.

53. Sen, A. (1993). « Des idiots rationnels ? Critique de la conception du comportement dans la théorie économique », p.87-116, dans Sen A., Éthique et économie, PUF, Coll. «Quadrige ».

54. Sen, A. (1999). Development as freedom, Oxford University Press.

55. Simon, H. (1983). Administration et processus de décision, Economica, Paris.

56. Shutz, A. (1987). Le chercheur et le quotidien, Editions Méridien, Klinksieck. 
57. Stien, E. (2012). L'impact de la culture sur le comportement de consommation: modélisation d'un comportement de consommation éthique ethnique, thèse de doctorat, Université d'Artois, Lens.

58. Strategor (2005). Politique générale de l'entreprise, Dunod, Paris.

59. Thaler, R.H. (2018). Misbehaving. Les découvertes de l'économie comportementale, Editions du Seuil, Paris.

60. Trompenaars, F. (1993). Ridind the Waves of Culture, Nocholas Brealey, London.

61. UNRISD (2014). Les facteurs sociaux du développement durables, Institut de Recherche des Nations Unies pour le Développement social, Synthèse 04, Genève, Suisse, 2014.

62. Williamson, E. 1994, L'économie des institutions, Inter Editions, Paris.

63. https://www.afdb.org/fr/countries/central-africa/Congo/Congoeconomic-outlook

64. https://www.banquemondiale.org/fr/country/Congo/overview

65. https://www.coface.com

66. https://www.fellah-trade.com

67. https://www.objectif-import-export.fr

68. https://www.tresor.economie.gouv.fr/Pays/CG/indicateurs-etconjoncturel

69. https://www.undp.org

70. https://www.unicongo.org/données-socioéconomiques-2012 
Annexe : questionnaire et données statistiques sur la culture Annexe 1. Formulation des thèmes, propositions et réponses : le questionnaire

\section{$T_{1}$-Croyances en Dieu ou dans les esprits au Congo}

$\mathrm{P}_{11}$-Dieu ou les esprits existent et influencent le cours de l'existence humaine : oui - non

P12-La sorcellerie, le fétichisme ou l'envooûtement est une réalité au Congo : oui - non

\section{$T_{2}$-La famille élargie et la solidarité au Congo}

$\mathrm{P}_{21}$-Je suis attaché à ma famille : oui - non

P22-La famille (élargie) est un lieu de solidarité et d'entraide : oui - non $\mathrm{P}_{23}$-Les gens cherchent de plus en plus l'entraide et la solidarité dans les mozikis (c'est-à-dire des mutuelles souvent informelles) : oui - non

\section{$T_{3}$-Le pouvoir, l'autorité et la responsabilité au Congo}

P31-L'aîné incarne souvent l'autorité ou la responsabilité dans la famille : oui - non

$\mathrm{P}_{32}$-Les militaires, policiers ou gendarmes incarnent un pouvoir ou une autorité au Congo : oui - non

P33-Le chef profite souvent de son pouvoir pour résoudre divers problèmes : oui - non

\section{$T_{4}-L a$ résolution de problèmes au Congo}

$\mathrm{P}_{41}$-La bonne information ou l'information officielle est facile à trouver au Congo : oui - non

Habituellement, pour s'en sortir au Congo ou pour résoudre un problème au Congo il faut :

P42- un réseau de relations ou des intermédiaires : oui - non

P43- de l'argent (pour corrompre quelqu'un) : oui - non

\section{$T_{5}$-La distraction ou les loisirs au Congo}

Habituellement, pour passer le temps ou pour se distraire, les gens s'orientent souvent vers (entourer la ou les bonnes réponses)

La lecture $=>$ La restauration $=>$ La musique $=>$ La boisson (nganda, caves, boîtes de nuit, bar...)

$\Rightarrow$ Les paris ou Jeux de loterie $=>$ Les jeux de société (ngola, jeux de cartes, dame) $\Rightarrow>$ Le sexe

$\Rightarrow$ la danse $\Rightarrow$ La télévision (sport sur écran géant ou petit écran) $\Rightarrow$ La causette $=>$ Le sport 


\section{$T_{6}$-La réalité des rapports humains (entre hommes, femmes et enfants) au}

Congo

Dans la réalité quotidienne, on constate souvent que :

$\mathrm{P}_{61}$ - la femme est soumise à l'homme : oui - non

$\mathrm{P}_{62}$ - l'homme travaille pour la femme et les enfants : oui - non

$\mathrm{P}_{63}$ - la femme s'occupe du foyer et des enfants : oui - non

P64- les travaux ménagers sont le lot de la femme et des enfants : oui non

P65- les enfants ne sont pas écoutés ou sont brimés (c'est-à-dire victimes de brutalité, vexation, soumission...) : oui - non

P66- certains groupes tribaux sont victimes de discrimination : oui - non

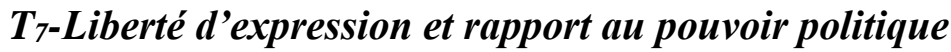

P71- Il y a la liberté d'expression ou la démocratie au Congo : oui - non

$\mathrm{P}_{72}$ - Le pouvoir politique en place au Congo inspire la peur ou la méfiance : oui - non

\section{$T_{8}$-Activité économique au Congo}

P81- Le congolais ne respecte pas le temps (il est souple au sujet du temps) : oui - non

P82- Je sais où chercher et espérer trouver du travail au Congo : oui - non P83- Pour être embauché au Congo il faut avoir de l'argent ou des relations (pistons) : oui - non

P84- Le commerce formel (déclaré) est le monopole des étrangers : oui - non P85- On peut entreprendre une activité avec un espoir de réussite au Congo : oui - non

P86- J'ai l'ambition de créer ma propre entreprise : oui - non

P87- Il y a des chances de réussite professionnelle en toute honnêteté au Congo : oui - non

P88- Mieux vaut immigrer ou tenter l'aventure à l'étranger pour s'en sortir : oui - non

P89- La vente ou les débits de boisson est une activité favorite des congolais : oui - non

P810- Au Congo l'État ou le service public travaille pour améliorer la vie des populations : oui - non

P811- Au Congo, la satisfaction des usagers ou des clients importe peu : oui non

\section{Ty-La mort au Congo}

P91- Les congolais meurent de plus en plus : oui - non

P92- La sorcellerie est une menace pour beaucoup de congolais : oui - non 
P93- Les congolais dépensent beaucoup plus d'argent pour l'enterrement que pour la santé : oui - non

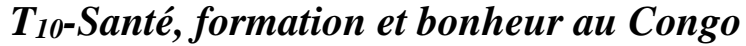

P101- Les malades sont bien soignés au Congo : oui - non

P102- Il y a des bonnes formations au Congo : oui - non

P103- On est heureux de vivre au Congo : oui - non

P104- Le congolais est optimiste sur son avenir au Congo : oui - non

\section{Annexe 2. Données statistiques construites sur la base du questionnaire}

Les tableaux contiennent les réponses données sur les différents thèmes et propositions. Dans les tableaux ci-dessous, FA indique les fréquences absolues et, FR les fréquences relatives. Au niveau du thème $\mathrm{T}_{5}$ (cf. Tableaux 3 et 4 ) on a les abréviations suivantes pour les distractions et loisirs :

L (lecture), R (restauration), M (musique), PJL (paris et jeux de loterie), JS (jeux de société), Se (sexe), Sp (sport), D (danse), B (boisson), C (causette) et $\mathrm{T}$ (télévision).

\begin{tabular}{|c|c|c|c|c|c|c|c|c|c|c|}
\hline \multicolumn{11}{|c|}{ Tableau 1} \\
\hline \multirow[t]{5}{*}{ Réponses } & \multicolumn{10}{|c|}{ Thèmes $T_{1}$ et $T_{2}$} \\
\hline & \multicolumn{4}{|c|}{ Mysticisme : thème $T_{1}$} & \multicolumn{6}{|c|}{ Famille, entraide et solidarité : thème $T_{2}$} \\
\hline & \multicolumn{4}{|c|}{ Propositions $\mathrm{P}_{1 \mathrm{j}}, \mathrm{j} \in\{1,2\}$} & \multicolumn{6}{|c|}{ Propositions $\mathrm{P}_{2 \mathrm{j}}, \mathrm{j} \in\{1,2,3\}$} \\
\hline & \multicolumn{2}{|c|}{$P_{11}$} & \multicolumn{2}{|c|}{$P_{12}$} & \multicolumn{2}{|c|}{$P_{21}$} & \multicolumn{2}{|c|}{$\mathrm{P}_{22}$} & \multicolumn{2}{|c|}{$P_{23}$} \\
\hline & FA & FR & FA & FR & FA & FR & FA & FR & FA & FR \\
\hline Oui & 122 & $97,6 \%$ & 123 & $98,4 \%$ & 115 & $92 \%$ & 95 & $76 \%$ & 112 & $89,6 \%$ \\
\hline Non & 2 & $1,6 \%$ & 2 & $1,6 \%$ & 10 & $8 \%$ & 29 & $23,2 \%$ & 13 & $10,4 \%$ \\
\hline Abstention & 1 & $0,8 \%$ & 0 & $0 \%$ & 0 & $0 \%$ & 1 & $0,8 \%$ & 0 & $0 \%$ \\
\hline Total & 125 & $100 \%$ & 125 & $100 \%$ & 125 & $100 \%$ & 125 & $100 \%$ & 125 & $100 \%$ \\
\hline
\end{tabular}

\begin{tabular}{|c|c|c|c|c|c|c|c|c|c|c|c|c|}
\hline \multicolumn{13}{|c|}{ Tableau 2} \\
\hline \multirow[t]{5}{*}{ Réponses } & \multicolumn{12}{|c|}{ Thèmes $\mathrm{T}_{3}$ et $\mathrm{T}_{4}$} \\
\hline & \multicolumn{6}{|c|}{ Pouvoir, autorité et responsabilité : thème $\mathrm{T}_{3}$} & \multicolumn{6}{|c|}{ Résolution de problèmes : thème $\mathrm{T}_{4}$} \\
\hline & \multicolumn{6}{|c|}{ Propositions $\mathrm{P}_{3 \mathrm{j}}, \mathrm{j} \in\{1,2,3\}$} & \multicolumn{6}{|c|}{ Propositions $\mathrm{P}_{4 \mathrm{j}}, \mathrm{j} \in\{1,2,3\}$} \\
\hline & \multicolumn{2}{|c|}{$\mathrm{P}_{31}$} & \multicolumn{2}{|c|}{$\mathrm{P}_{32}$} & \multicolumn{2}{|c|}{$\mathrm{P}_{33}$} & \multicolumn{2}{|c|}{$\mathrm{P}_{41}$} & \multicolumn{2}{|c|}{$\mathrm{P}_{42}$} & \multicolumn{2}{|c|}{$\mathrm{P}_{43}$} \\
\hline & FA & FR & FA & FR & FA & FR & FA & FR & FA & FR & FA & FR \\
\hline Oui & 112 & $\begin{array}{c}89,6 \\
\%\end{array}$ & 113 & $\begin{array}{c}90,4 \\
\%\end{array}$ & 118 & $\begin{array}{c}94,4 \\
\%\end{array}$ & 25 & $20 \%$ & 119 & $\begin{array}{c}95,2 \\
\%\end{array}$ & 119 & $\begin{array}{c}95,2 \\
\%\end{array}$ \\
\hline Non & 13 & $\begin{array}{c}10,4 \\
\%\end{array}$ & 11 & $8,8 \%$ & 6 & $4,8 \%$ & 97 & $\begin{array}{c}77,6 \\
\%\end{array}$ & 4 & $3,2 \%$ & 5 & $4 \%$ \\
\hline Abstention & 0 & $0 \%$ & 1 & $0,8 \%$ & 1 & $0,8 \%$ & 3 & $2,4 \%$ & 2 & $1,6 \%$ & 1 & $0,8 \%$ \\
\hline Total & 125 & $100 \%$ & 125 & $100 \%$ & 125 & $100 \%$ & 125 & $100 \%$ & 125 & $100 \%$ & 125 & $100 \%$ \\
\hline
\end{tabular}


Tableau 3

\begin{tabular}{|c|c|c|c|c|c|c|c|c|c|c|c|c|}
\hline Thème & \multicolumn{12}{|c|}{ Distractions et Loisirs : Thème $\mathrm{T}_{5}$} \\
\hline Activités & \multicolumn{2}{|c|}{$\mathrm{L}$} & \multicolumn{2}{|c|}{$\mathrm{R}$} & \multicolumn{2}{|c|}{$\mathrm{M}$} & \multicolumn{2}{|c|}{$\mathrm{B}$} & \multicolumn{2}{|c|}{ PJL } & \multicolumn{2}{|c|}{ JS } \\
\hline \multirow{2}{*}{$\begin{array}{l}\text { Fréquence } \\
\text { de choix }\end{array}$} & FA & FR & FA & FR & FA & FR & FA & FR & FA & FR & FA & FR \\
\hline & 12 & $9,6 \%$ & 14 & $\begin{array}{c}11,2 \\
\%\end{array}$ & 51 & $\begin{array}{c}40,8 \\
\%\end{array}$ & 105 & $84 \%$ & 75 & $60 \%$ & 52 & $\begin{array}{c}41,6 \\
\%\end{array}$ \\
\hline $\begin{array}{l}\text { Rang de } \\
\text { l'activité } \\
\text { selon la } \\
\text { fréquence }\end{array}$ & \multicolumn{2}{|c|}{10} & \multicolumn{2}{|c|}{9} & \multicolumn{2}{|c|}{5} & \multicolumn{2}{|c|}{1} & \multicolumn{2}{|c|}{3} & \multicolumn{2}{|c|}{4} \\
\hline
\end{tabular}

\begin{tabular}{|c|c|c|c|c|c|c|c|c|c|c|}
\hline \multicolumn{11}{|c|}{ Tableau 4} \\
\hline Thème & \multicolumn{10}{|c|}{ Distractions et Loisirs : thème $T_{5}$} \\
\hline Activités & \multicolumn{2}{|c|}{$\mathrm{Se}$} & \multicolumn{2}{|c|}{$\mathrm{D}$} & \multicolumn{2}{|c|}{$\mathrm{T}$} & \multicolumn{2}{|c|}{$\mathrm{C}$} & \multicolumn{2}{|c|}{ Sp } \\
\hline \multirow{2}{*}{$\begin{array}{l}\text { Fréquence } \\
\text { de choix }\end{array}$} & FA & FR & FA & FR & FA & FR & FA & FR & FA & FR \\
\hline & 52 & $41,6 \%$ & 28 & $22,4 \%$ & 88 & $70,4 \%$ & 50 & $40 \%$ & 49 & $39,2 \%$ \\
\hline $\begin{array}{l}\text { Rang de } \\
\text { l'activité } \\
\text { selon la } \\
\text { fréquence }\end{array}$ & \multicolumn{2}{|c|}{4} & \multicolumn{2}{|c|}{8} & \multicolumn{2}{|c|}{2} & \multicolumn{2}{|c|}{6} & \multicolumn{2}{|c|}{7} \\
\hline
\end{tabular}

\begin{tabular}{|c|c|c|c|c|c|c|c|c|c|c|c|c|}
\hline \multicolumn{13}{|c|}{ Tableau 5} \\
\hline \multirow[t]{4}{*}{ Réponses } & \multicolumn{12}{|c|}{ Réalité des Rapports Humains : Thème $\mathrm{T}_{6}$} \\
\hline & \multicolumn{12}{|c|}{ Propositions $\mathrm{P}_{\mathrm{ij}}$ où $\mathrm{i}=6$ et $\mathrm{j} \in\{1,2,3,4,5,6\}$} \\
\hline & \multicolumn{2}{|c|}{$\mathrm{P}_{61}$} & \multicolumn{2}{|c|}{$\mathrm{P}_{62}$} & \multicolumn{2}{|c|}{$\mathrm{P}_{63}$} & \multicolumn{2}{|c|}{$\mathrm{P}_{64}$} & \multicolumn{2}{|c|}{$\mathrm{P}_{65}$} & \multicolumn{2}{|c|}{$\mathrm{P}_{66}$} \\
\hline & FA & FR & FA & FR & FA & FR & FA & FR & FA & FR & FA & FR \\
\hline Oui & 77 & $\begin{array}{c}61,6 \\
\%\end{array}$ & 112 & 89,6 & 118 & $\begin{array}{c}94,4 \\
\%\end{array}$ & 117 & $\begin{array}{c}93,6 \\
\%\end{array}$ & 89 & $\begin{array}{c}71,2 \\
\%\end{array}$ & 112 & $\begin{array}{c}89,6 \\
\%\end{array}$ \\
\hline Non & 48 & $\begin{array}{c}38,4 \\
\%\end{array}$ & 13 & $\begin{array}{c}10,4 \\
\%\end{array}$ & 6 & $4,8 \%$ & 7 & $5,6 \%$ & 31 & $\begin{array}{c}24,8 \\
\%\end{array}$ & 9 & $7,2 \%$ \\
\hline Abstention & 0 & $0 \%$ & 0 & $0 \%$ & 1 & $0,8 \%$ & 1 & $0,8 \%$ & 5 & $4 \%$ & 4 & $3,2 \%$ \\
\hline Total & 125 & $100 \%$ & 125 & $100 \%$ & 125 & $100 \%$ & 125 & $100 \%$ & 125 & $100 \%$ & 125 & $100 \%$ \\
\hline
\end{tabular}

\begin{tabular}{|c|c|c|c|c|c|c|c|c|c|c|}
\hline \multicolumn{11}{|c|}{ Tableau 6} \\
\hline \multirow{5}{*}{ Réponses } & \multicolumn{10}{|c|}{ Thèmes $\mathrm{T}_{7}$ et $\mathrm{T}_{9}$} \\
\hline & \multicolumn{4}{|c|}{ Liberté d'expression : thème $\mathrm{T}_{7}$} & \multicolumn{6}{|c|}{ Mort et sorcellerie : thème $\mathrm{T}_{9}$} \\
\hline & \multicolumn{4}{|c|}{ Propositions $\mathrm{P}_{7 \mathrm{j}}, \mathrm{j} \in\{1,2\}$} & \multicolumn{6}{|c|}{ Propositions $P_{9 j}, j \in\{1,2,3\}$} \\
\hline & \multicolumn{2}{|c|}{$\mathrm{P}_{71}$} & \multicolumn{2}{|c|}{$\mathrm{P}_{72}$} & \multicolumn{2}{|c|}{$\mathrm{P}_{91}$} & \multicolumn{2}{|c|}{$\mathrm{P}_{92}$} & \multicolumn{2}{|c|}{$\mathrm{P}_{93}$} \\
\hline & FA & FR & FA & FR & FA & FR & FA & FR & FA & FR \\
\hline Oui & 3 & $2,4 \%$ & 115 & $92 \%$ & 121 & $96,8 \%$ & 120 & $96 \%$ & 122 & $97,6 \%$ \\
\hline Non & 121 & $96,8 \%$ & 8 & $6,4 \%$ & 3 & $2,4 \%$ & 3 & $2,4 \%$ & 2 & $1,6 \%$ \\
\hline Abstention & 1 & $0,8 \%$ & 2 & $1,6 \%$ & 1 & $0,8 \%$ & 2 & $1,6 \%$ & 1 & $0,8 \%$ \\
\hline Total & 125 & $100 \%$ & 125 & $100 \%$ & 125 & $100 \%$ & 125 & $100 \%$ & 125 & $100 \%$ \\
\hline
\end{tabular}


Tableau 7

\begin{tabular}{|c|c|c|c|c|c|c|c|c|c|c|c|c|}
\hline \multirow[t]{3}{*}{ Réponses } & \multicolumn{12}{|c|}{ Activité économique : Thème $\mathrm{T}_{8}$ et propositions $\mathrm{P}_{8 \mathrm{j}}, \mathrm{j} \in\{1,2,3,4,5,6\}$} \\
\hline & \multicolumn{2}{|c|}{$\mathrm{P}_{81}$} & \multicolumn{2}{|c|}{$\mathrm{P}_{82}$} & \multicolumn{2}{|c|}{$\mathrm{P}_{83}$} & \multicolumn{2}{|c|}{$\mathrm{P}_{84}$} & \multicolumn{2}{|c|}{$\mathrm{P}_{85}$} & \multicolumn{2}{|c|}{$\mathrm{P}_{86}$} \\
\hline & FA & FR & FA & FR & FA & FR & FA & FR & FA & FR & FA & FR \\
\hline Oui & 117 & $\begin{array}{c}93,6 \\
\%\end{array}$ & 30 & $24 \%$ & 120 & $96 \%$ & 118 & $\begin{array}{c}94,4 \\
\%\end{array}$ & 62 & $\begin{array}{c}49,6 \\
\%\end{array}$ & 110 & $88 \%$ \\
\hline Non & 7 & $5,6 \%$ & 92 & $\begin{array}{c}73,6 \\
\%\end{array}$ & 4 & $3,2 \%$ & 4 & $3,2 \%$ & 59 & $\begin{array}{c}47,2 \\
\%\end{array}$ & 12 & $9,6 \%$ \\
\hline Abstention & 1 & $0,8 \%$ & 3 & $2,4 \%$ & 1 & $0,8 \%$ & 3 & $2,4 \%$ & 4 & $3,2 \%$ & 3 & $2,4 \%$ \\
\hline Total & 125 & $100 \%$ & 125 & $100 \%$ & 125 & $\begin{array}{c}100 \\
\%\end{array}$ & 125 & $100 \%$ & 125 & $100 \%$ & 125 & $\begin{array}{c}100 \\
\%\end{array}$ \\
\hline
\end{tabular}

Tableau 8

\begin{tabular}{|c|c|c|c|c|c|c|c|c|c|c|}
\hline \multirow{2}{*}{ Réponses } & \multicolumn{8}{|c|}{ Activité économique : Thème $\mathrm{T}_{8}$ et propositions $\mathrm{P}_{8 \mathrm{j}}, \mathrm{j} \in\{7,8,9,10,11\}$} \\
\cline { 2 - 13 } & \multicolumn{2}{|c|}{$\mathrm{P}_{87}$} & \multicolumn{2}{|c|}{$\mathrm{P}_{88}$} & \multicolumn{2}{c|}{$\mathrm{P}_{89}$} & \multicolumn{2}{c|}{$\mathrm{P}_{810}$} & \multicolumn{2}{c|}{$\mathrm{P}_{811}$} \\
\cline { 2 - 13 } & FA & FR & FA & FR & FA & FR & FA & FR & FA & FR \\
\hline Oui & 66 & $52,8 \%$ & 91 & $72,8 \%$ & 120 & $96 \%$ & 12 & $9,6 \%$ & 104 & 83,2 \\
\hline Non & 57 & $45,6 \%$ & 30 & $24 \%$ & 3 & $2,4 \%$ & 110 & $88 \%$ & 20 & $16 \%$ \\
\hline Abstention & 2 & $1,6 \%$ & 4 & $3,2 \%$ & 2 & $1,6 \%$ & 3 & $2,4 \%$ & 1 & $0,8 \%$ \\
\hline Total & 125 & $100 \%$ & 125 & $100 \%$ & 125 & $100 \%$ & 125 & $100 \%$ & 125 & $100 \%$ \\
\hline
\end{tabular}

Tableau 9

\begin{tabular}{|c|c|c|c|c|c|c|c|c|}
\hline \multicolumn{10}{|c|}{ Tableau 9 } \\
\hline \multirow{2}{*}{ Réponses } & \multicolumn{7}{|c|}{ Santé, formation et bonheur : Thèmes $\mathrm{T}_{10}$ et propositions $\mathrm{P}_{10 \mathrm{j}}, \mathrm{j} \in\{1,2,3,4\}$} \\
\cline { 2 - 9 } & \multicolumn{3}{|c|}{$\mathrm{P}_{101}$} & \multicolumn{2}{|c|}{$\mathrm{P}_{102}$} & \multicolumn{2}{|c|}{$\mathrm{P}_{103}$} & \multicolumn{2}{c|}{$\mathrm{P}_{104}$} \\
\cline { 2 - 9 } & FA & FR & FA & FR & FA & FR & FA & FR \\
\hline Oui & 4 & $3,2 \%$ & 57 & $45,6 \%$ & 50 & $40 \%$ & 66 & $52,8 \%$ \\
\hline Non & 120 & $96 \%$ & 67 & $53,6 \%$ & 74 & $59,2 \%$ & 58 & $46,4 \%$ \\
\hline Abstention & 1 & $0,8 \%$ & 1 & $0,8 \%$ & 1 & $0,8 \%$ & 1 & $0,8 \%$ \\
\hline Total & 125 & $100 \%$ & 125 & $100 \%$ & 125 & $100 \%$ & 125 & $100 \%$ \\
\hline
\end{tabular}

